\title{
Development and Validation of a Stability-Indicating Method for Perillyl Alcohol Incorporated in Poly(lactide-co-glycolide) Nanoparticles and Stress Degradation Studies
}

\author{
Breno M. Marson, ${ }^{a}$ Raquel O. Vilhena, ${ }^{a}$ Flavia L. D. Pontes, ${ }^{a}$ Najeh M. Khalil ${ }^{b}$ and \\ Roberto Pontarolo*,a
}

${ }^{a}$ Departamento de Farmácia, Universidade Federal do Paraná (UFPR), 80210-170 Curitiba-PR, Brazil

${ }^{b}$ Departamento de Farmácia, Universidade Estadual do Centro-Oeste (UNICENTRO), 85040-080 Guarapuava-PR, Brazil

\begin{abstract}
Perillyl alcohol has been studied in the treatment of cancer disease. However, its high toxicity is a drawback, which can be overcome by its incorporation in nanostructured systems. The aim of this work was to develop and validate a chromatographic method for determination of perillyl alcohol encapsulation efficiency in a polymeric nanoparticles formulation and evaluation of the presence of related degradation products. Perillyl alcohol was subjected to forced conditions of hydrolysis (acidic, alkaline and neutral), oxidation, photolysis and thermal stress, as suggested in the International Conference of Harmonization (ICH) guidelines. The drug showed significant degradation under acidic conditions. The degradation products could be adequately separated on an XBridge C18 column $(100 \times 2.1 \mathrm{~mm}, 3.5 \mu \mathrm{m})$ using isocratic elution $\left(350 \mu \mathrm{L} \mathrm{min}^{-1}\right)$ of water/ acetonitrile $(65: 35, \mathrm{v} / \mathrm{v})$ at $210 \mathrm{~nm}$. Data from validation studies demonstrated that the method is selective, linear (coefficient of determination $\left.\left(\mathrm{r}^{2}\right)>0.999\right)$ over the range of $20.0-80.0 \mu \mathrm{g} \mathrm{mL}^{-1}$, precise (relative standard deviation (RSD) $<2.0 \%$ ), accurate $(98.07$ to $101.99 \%$ ) and robust for minor changes. The method was successfully applied to determine the encapsulation efficiency of perillyl alcohol in polymeric nanoparticles, both for product development and for quality control purposes. After nanoparticles production, the presence of degradation products was not observed indicating that the single-emulsion solvent-evaporation technique used does not favor chemical degradation of the drug.
\end{abstract}

Keywords: perillyl alcohol, stability-indicating, validation, nanoparticles, degradation products

\section{Introduction}

Perillyl alcohol (POH; IUPAC name: [4-(prop-1-en-2-yl) cyclohex-1-en-yl]methanol; $\mathrm{C}_{10} \mathrm{H}_{16} \mathrm{O}$; MW: 152.2344 Da; Figure 1) is a naturally occurring cyclic monoterpene found in essential oils of plants and citrus fruits, derived from the mevalonate pathway. ${ }^{1,2}$ Medical interest in this compound has been generated by several researches showing that $\mathrm{POH}$ has been able to demonstrate activity against a variety of tumor models, such as adenocarcinoma, brain, breast, colon, gliomas, leukemic cells, liver, lung, pancreas, prostate and skin. ${ }^{2-7}$ However, the results of phase I and II clinical trials showed nausea, vomiting and loose stools identified as common toxicities with rare leukocytosis, thrombocytosis, lethargy, renal tubular degeneration with elevated serum creatinine and gastritis. ${ }^{8-10}$

*e-mail: pontarolo@ufpr.br

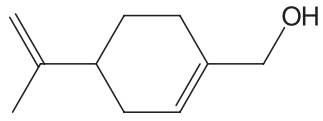

Figure 1. Chemical structure of perillyl alcohol.

Chemotherapeutic agents harm healthy tissues, leading to systemic toxicity and adverse effects that greatly limit the maximum tolerated dose of anti-cancer drugs and thus restrict their therapeutic efficacy. ${ }^{11}$ One alternative to overcome these problems is the use of polymeric nanoparticles, which are defined as particulate dispersions or solid particles with a size in the range of $10-1000 \mathrm{~nm}$. Poly(lactic-co-glycolic acid) (PLGA) is one of the most successfully developed biodegradable polymers and has attracted considerable attention due to its attractive properties, such as its low risk of toxicity, high biodegradability and biocompatibility, protection of molecules from premature degradation, improvement 
of solubility, promotion of controlled drug release and drug targeting. Furthermore, when a drug is loaded into nanostructures the pharmacokinetic parameters are modified, providing improvements in absorption, bioavailability, plasma circulation time and reduction of clearance, consequently increasing the drug's mean half-life. ${ }^{11-17}$

The physico-chemical characterization of drug carriers is highly important, and the determination of drug content is especially complex due to the small size and difficulty in separation of free and loaded drug. A technique which has been used to assay drug loading and determination of encapsulation efficiency is the analysis of the clear supernatant following separation of the nanoparticles from the aqueous medium by a centrifugation technique. The drug content in nanoparticles can be calculated by the difference between the total and free estimated drug concentrations. ${ }^{18}$

The literature reports few methods for determination of POH from different sample types. The most common technique used is the gas chromatography coupled to mass spectrometry (GC-MS) for both biological matrices such as plasma and urine, and non-biological matrices such as the volatile fraction of plant extracts. ${ }^{19-24}$ Methods by liquid chromatography (LC) techniques are also described in the literature, such as liquid chromatography-diode array detection (LC-DAD), ${ }^{25-29}$ liquid chromatographyelectrochemical detection (LC-ECD) ${ }^{30}$ and liquid chromatography-fluorescence detection (LC-FLD). ${ }^{31}$ These papers are devoted to describing chromatographic methods for analytical and bioanalytical quantification of $\mathrm{POH}$, and none of these cases comprise a degradation behavior study. Forced degradation studies allow the identification of factors that affect drug stability and allow the selection of suitable storage and handling conditions. Furthermore, they can provide information about specificity for adequate method development.

As the nanoparticles used in this study were obtained by the single-emulsion solvent-evaporation technique, with emulsification by ultrasonication and organic solvent elimination by evaporation under vacuum and temperature, the assessment of degradation behavior is crucial for the method development. Furthermore, since the production of such nanoparticles involves conditions that are not very mild, such as ultrasound and temperature, the availability of an analytical method capable of identifying degradation can provide relevant information about the production process. Thus, the aim of this work was to develop and validate a stability-indicating method by LC-DAD, suitable for quantifying $\mathrm{POH}$ in polymeric nanostructures, both for product development and for quality control purposes. The present study was carried out to report the degradation products of the drug formed under International Conference on Harmonization (ICH)recommended stress conditions of hydrolysis, oxidation, humidity, dry heat and photolysis. ${ }^{32,33}$

\section{Experimental}

\section{Chemicals and reagents}

POH (> 96.0\%) was obtained from Sigma-Aldrich (St. Louis, MO, USA). Acetonitrile and methanol, HPLC grade, were purchased from Tedia (Fairfield, OH, USA). Ultrapure water was obtained using a Milli-Q purification system from Millipore (Bedford, MA, USA). PLGA (Resomer RG 50:50 H; MW ca. 40-75 kDa, inherent viscosity 0.45-0.6 $\mathrm{dL} \mathrm{g}^{-1}$ ) and polyvinyl alcohol (PVA, MW ca. $31 \mathrm{kDa}, 88 \%$ hydrolyzed) were obtained from Sigma-Aldrich (St. Louis, MO, USA). Methylene chloride was obtained from Dinâmica (São Paulo, SP, Brazil). Hydrochloric acid (36.5-38\%) was obtained from Mallinckrodt Baker (Ecatepec de Morelos, Méx, México). Sodium hydroxide (99\%) was obtained from Merck KGaA (Darmstadt, Hesse, Germany). Hydrogen peroxide (30\%) was obtained from Labsynth (São Paulo, SP, Brazil).

\section{Apparatus and software}

LC-DAD analyses were carried out in an Agilent 1100 HPLC Series (Agilent Technologies, Santa Clara, CA, USA), with a quaternary pump (G1311A), degasser (G1379A), thermostated column oven (G1316A), ALS autosampler manager (G1329A) and diode array detector (G1315B). The chromatographic system was operated using ChemStation for LC 3D system software (B.04.03 (16)). Analyses were performed at $25{ }^{\circ} \mathrm{C}$ on an XBridge $\mathrm{C} 18$ column $(100 \times 2.1 \mathrm{~mm}, 3.5 \mu \mathrm{m}$; Waters, Milford, MA, USA) coupled with an XBridge $\mathrm{C} 18$ guard column $(10 \times 2.1 \mathrm{~mm}$, $3.5 \mu \mathrm{m}$; Waters, Milford, MA). The mobile phase used was a water/acetonitrile mixture $(65: 35, \mathrm{v} / \mathrm{v})$. The isocratic flow rate was $350 \mu \mathrm{L} \mathrm{min}^{-1}$, the injection volume was $20 \mu \mathrm{L}$ and detection was performed at $210 \mathrm{~nm}$. Mean particle size were determined after proper dilution by dynamic light scattering (NanoDLS, Brookhaven Instruments Corp., NY, USA). The system was operated using Particle Sizing software (version 4.61). Zeta potential was measured after proper dilution in a cylindrical teflon beaker of $10 \mathrm{~mL}$ with an oscillating displacement piston by Stabino Particle Charge Mapping (Stabino ${ }^{\circ}$, Particle Metrix GmbH, Meerbusch, Germany). The system was operated using Stabino Control software (version 2.00.27.02). 


\section{Stock and working standard solutions}

A stock solution of $\mathrm{POH}\left(10 \mathrm{mg} \mathrm{mL}^{-1}\right)$ was prepared in methanol, and transferred to individual glass flasks protected from light and stored under refrigeration (storage at $2-8{ }^{\circ} \mathrm{C}$, for 30 days). The working standard solutions were prepared in appropriate concentrations by dilution of the stock solution in the mobile phase under low light exposure and filtered through a polyvinylidene fluoride (PVDF) syringe filter (13 mm diameter, $0.22 \mu \mathrm{m}$ pore size; Millipore Millex, Billerica, MA, USA) prior to injection.

\section{Forced degradation studies}

In order to develop a stability-indicating method, a forced degradation study was conducted with $\mathrm{POH}$ under various stress conditions. ${ }^{32}$ From the $\mathrm{POH}$ stock solution, intermediate solutions $\left(1 \mathrm{mg} \mathrm{mL} \mathrm{mL}^{-1}\right)$ were prepared and submitted individually to different stress conditions. After exposure the intermediate solutions were diluted to target concentrations of $200 \mu \mathrm{g} \mathrm{mL} \mathrm{m}^{-1}$ in the mobile phase under low light exposure (except photodegradation) and filtered through a PVDF syringe filter (13 mm diameter, $0.22 \mu \mathrm{m}$ pore size; Millipore Millex, Billerica, MA, USA) prior to injection.

For acidic degradation conditions, intermediate solutions were kept in $1 \mathrm{~mol} \mathrm{~L}^{-1} \mathrm{HCl}$ at room temperature for $36 \mathrm{~h}$ and neutralized $(\mathrm{pH} \mathrm{7.4)}$ before analysis by adding an appropriate amount of $\mathrm{NaOH}\left(1 \mathrm{~mol} \mathrm{~L}^{-1}\right)$. For alkaline degradation conditions, intermediate solution was kept in $1 \mathrm{~mol} \mathrm{~L}^{-1} \mathrm{NaOH}$ at room temperature for $36 \mathrm{~h}$ and neutralized ( $\mathrm{pH}$ 7.4) before analysis by adding an appropriate amount of $\mathrm{HCl}\left(1 \mathrm{~mol} \mathrm{~L}^{-1}\right)$. Oxidative degradation was performed by keeping the intermediate solution with $15 \%$ hydrogen peroxide at room temperature for $36 \mathrm{~h}$. The dry heat degradation study was done by keeping the intermediate solution diluted in methanol (amber flask without headspace) in an oven at $60{ }^{\circ} \mathrm{C}$ for 7 days. The thermal humidity degradation study was done by keeping the intermediate solution diluted in a methanol/ water mixture $(1: 1, \mathrm{v} / \mathrm{v})$ (amber flask without headspace) in an oven at $60{ }^{\circ} \mathrm{C}$ for 7 days. The photodegradation study was done by exposing the intermediate solution diluted in methanol (transparent flask without headspace) to $1.2 \times 10^{6} \mathrm{~lx}$ h of fluorescent light and $200 \mathrm{~W} \mathrm{~h} \mathrm{~m}^{-2} \mathrm{UV}$ light in a photostability chamber.

\section{Nanoparticles and sample preparation}

The nanoparticles were obtained by the singleemulsion solvent-evaporation technique, as described in the literature. ${ }^{34}$ Briefly, POH (10 mg) and PLGA (25 mg) were separately dissolved in 1.0 and $0.5 \mathrm{~mL}$ of methylene chloride, respectively, at room temperature. This organic phase was rapidly poured into $5 \mathrm{~mL}$ of PVA aqueous solution $(1.0 \%, \mathrm{~m} / \mathrm{v})$ and emulsified by sonication for three cycles of 2 min (Unique ${ }^{\circledR}$ Ultrasonic Mixing, Brazil), resulting in an oil-in-water $(\mathrm{O} / \mathrm{W})$ emulsion. After that, the organic solvent was immediately eliminated by evaporation under vacuum $\left(10 \mathrm{~min}\right.$ at $\left.37{ }^{\circ} \mathrm{C}\right)$. The nanoparticles were recovered by centrifugation $(14,857 \times \mathrm{g}, 30 \mathrm{~min}$, $4{ }^{\circ} \mathrm{C}$; Eppendorf Centrifuge $5810 \mathrm{R}$, Germany), then the recovered nanoparticles were washed twice with water using previously described centrifugation. Supernatants were mixed and stored for posterior analysis.

The amount of $\mathrm{POH}$ incorporated into the nanoparticles was determined by analysis of the clear supernatant following separation of the nanoparticles from the aqueous medium by a centrifugation technique previously described. The supernatant was diluted with mobile phase to a final volume of $10 \mathrm{~mL}$ and was subjected to ultrasonic bath for $5 \mathrm{~min}$. Then diluted to appropriate concentration by dilution in the mobile phase, under low light exposure, and filtered through a PVDF syringe filter (13 mm diameter, $0.22 \mu \mathrm{m}$ pore size; Millipore Millex, Billerica, MA, USA) prior to injection.

\section{Analytical method validation}

Validation was performed in accordance with the ICH for quantitative methods, considering the following parameters: selectivity, linearity, accuracy, precision and robustness. ${ }^{35}$ The selectivity of the chromatographic method was evaluated by comparing the chromatograms of matrix components (nanoparticles excipients), degradation products and sample diluent with the response obtained for $\mathrm{POH}$. The ability of the method in discriminate $\mathrm{POH}$, even in the presence of possible interferences, was evaluated by demonstrating that for the same $\mathrm{POH}$ retention time there was no coelution of any other component. The peak purity for $\mathrm{POH}$ was assessed with a photodiode array detector. Additionally, selectivity was evaluated by comparing the slopes of two analytical curves. An analytical curve obtained with the standard solution was compared with another analytical curve obtained with the diluted samples spiked with the analyte, at the same concentrations used to prepare the first curve. These curves were prepared in triplicate at concentrations ranging from 20 to $80 \mu \mathrm{g} \mathrm{mL}^{-1}$ $(\mathrm{POH})$. The data were analyzed with linear regression analysis and an analytical curve was obtained. The slopes obtained from both analytical curves were compared and analyzed using Student's $t$-test. The linearity was assessed 
by three calibration curves at seven different concentrations (20.0, 30.0, 40.0, 50.0, 60.0, 70.0 and $80.0 \mu \mathrm{gL}^{-1}$ ) after proper dilution of the stock solution. The slope, intercept and coefficient of determination $\left(\mathrm{r}^{2}\right)$ were calculated by linear regression performed on the concentration $v s$. peak area using the least squares method. The accuracy was determined as the recovery by the standard addition method. Nine preparations at three levels around the specification target (POH, 20.0, 50.0 and $80.0 \mu \mathrm{g} \mathrm{mL}-1$ ) were analyzed, three preparations per level. Samples were prepared at $30 \%$ of the target analyte concentration and analyzed to confirm the actual values, and then they were spiked with the standard solution. The percentage recovery was calculated and the relationship between the average concentration determined experimentally, and the equivalent theoretical concentration was determined. The precision was determined at two levels: intra-day and inter-day. The intra-day precision was determined by analyzing nine preparations at three levels around the specification target (POH, 20.0, 50.0 and $80.0 \mu \mathrm{g} \mathrm{mL}^{-1}$ ), three preparations per level. All solutions were prepared by the same analyst under identical experimental conditions on the same day. The inter-day precision was performed by analyzing nine new POH solutions in the same way as for intra-day precision, but prepared by a second analyst, after two days. The results are expressed as the relative standard deviation (RSD), and Student's $t$-test was performed to compare the results of the analytes in each assay. The robustness was evaluated by changing the experimental conditions to analyze POH solutions with identical concentration $\left(20.0 \mu \mathrm{g} \mathrm{mL}^{-1}\right)$. The parameters were varied: isocratic flow (340 to $360 \mu \mathrm{L} \mathrm{min}{ }^{-1}$ ), temperature ( 23 and $\left.28{ }^{\circ} \mathrm{C}\right)$, mobile phase composition ratio $( \pm 2 \%)$ and two different columns. The results were evaluated as percentage recovery and RSD, when compared to the normal conditions. Furthermore, the $\mathrm{POH}$ purity peak and resolution between $\mathrm{POH}$ and degradation peaks were evaluated. Stability studies for POH included evaluation of sample (stored in sample manager at $20^{\circ} \mathrm{C}$ for $12 \mathrm{~h}$ ), and evaluation of stock standard solution (stored at $2-8{ }^{\circ} \mathrm{C}$ for 7,14 and 30 days). Student's $t$-test was performed to compare the results of freshly prepared sample and standard solutions with those obtained after storage in different conditions.

\section{Results and Discussion}

Preliminary tests were conducted to select an initial LC method. Several trials were conducted with different isocratic or gradient mobile phases containing different solvent, stationary phase, particle size, column temperature and detection wavelength. Parameters such as elution time, asymmetry, tailing factor and plate number were adjusted for the proposed preliminary LC method and the selected column was an XBridge C18 $(100 \times 2.1 \mathrm{~mm}, 3.5 \mu \mathrm{m})$. Since there are no reports about $\mathrm{POH}$ degradation behavior in the literature to support the initial tests and the goal of this study was to get primary degradations, it was decided to start with mild forced degradation conditions, such as: acidic, $0.1 \mathrm{~mol} \mathrm{~L}^{-1} \mathrm{HCl}$; alkaline, $0.1 \mathrm{~mol} \mathrm{~L}^{-1} \mathrm{NaOH}$; oxidative, $3 \%$ hydrogen peroxide; dry heat, $40^{\circ} \mathrm{C}$; thermal humidity, room temperature; photodegradation, $1.2 \times 10^{6} \mathrm{~lx}$ h fluorescent light and $200 \mathrm{~W} \mathrm{~h} \mathrm{~m}^{-2} \mathrm{UV}$ light. As POH is liquid, viscous and volatile at room temperature, the study was conducted from $\mathrm{POH}$ stock solution by preparing intermediate solutions, at $1 \mathrm{mg} \mathrm{mL}^{-1}$, that were submitted individually to different stress conditions. After each stress time exposure the intermediate solutions were diluted to analytical concentration. This way allowed more precision in sample taking, facilitating comparisons between peak areas and chromatographic profile of the same stress conditions, apart from lower control sample preparations. The intermediate solution volumes were designed to enable several dilutions, and allowed the evaluation of different exposure times. Once the analytical solutions were obtained by dilution of intermediate solutions, it was possible to neutralize the acidic and alkaline conditions. Besides, this procedure provided the dilution of stressing agents such as hydrogen peroxide, for example. The blanks of each condition were prepared in the same way, including dilutions and neutralizing steps. Even after 10 days of exposure to mild forced degradation conditions, no degradation or decay of active pharmaceutical ingredient (API) was observed. Based on the preliminary results, it was decided to increase the intensity of the stress conditions, passing to: acidic, $1 \mathrm{~mol} \mathrm{~L}{ }^{-1} \mathrm{HCl}$; alkaline, $1 \mathrm{~mol} \mathrm{~L}-1 \mathrm{NaOH}$; oxidative, $15 \%$ hydrogen peroxide; dry heat, $60{ }^{\circ} \mathrm{C}$; thermal humidity, $60{ }^{\circ} \mathrm{C}$. For photodegradation conditions an increase in exposure was not considered because this is already the upper limit used to perform photodegradation stability studies. ${ }^{36}$ After $36 \mathrm{~h}$ of exposure, all samples showed some degradation and decay of the $\mathrm{POH}$ peak area. The degradation profiles of acidic and alkaline conditions are presented in Figure 2, including blank and final time. Stress acidic conditions presented four degradation products (DP1, DP3, DP4 and DP5). Stress alkaline conditions presented two degradation products (DP2 and DP3). The degradation product identified as DP3 was also observed in the oxidative, dry heat and thermal humidity conditions. The degradation product identified as DP5 was also observed in the oxidative and dry heat stress conditions.

The degradation percentages obtained were considered appropriate since the decay values were $10-25 \%$. Values 


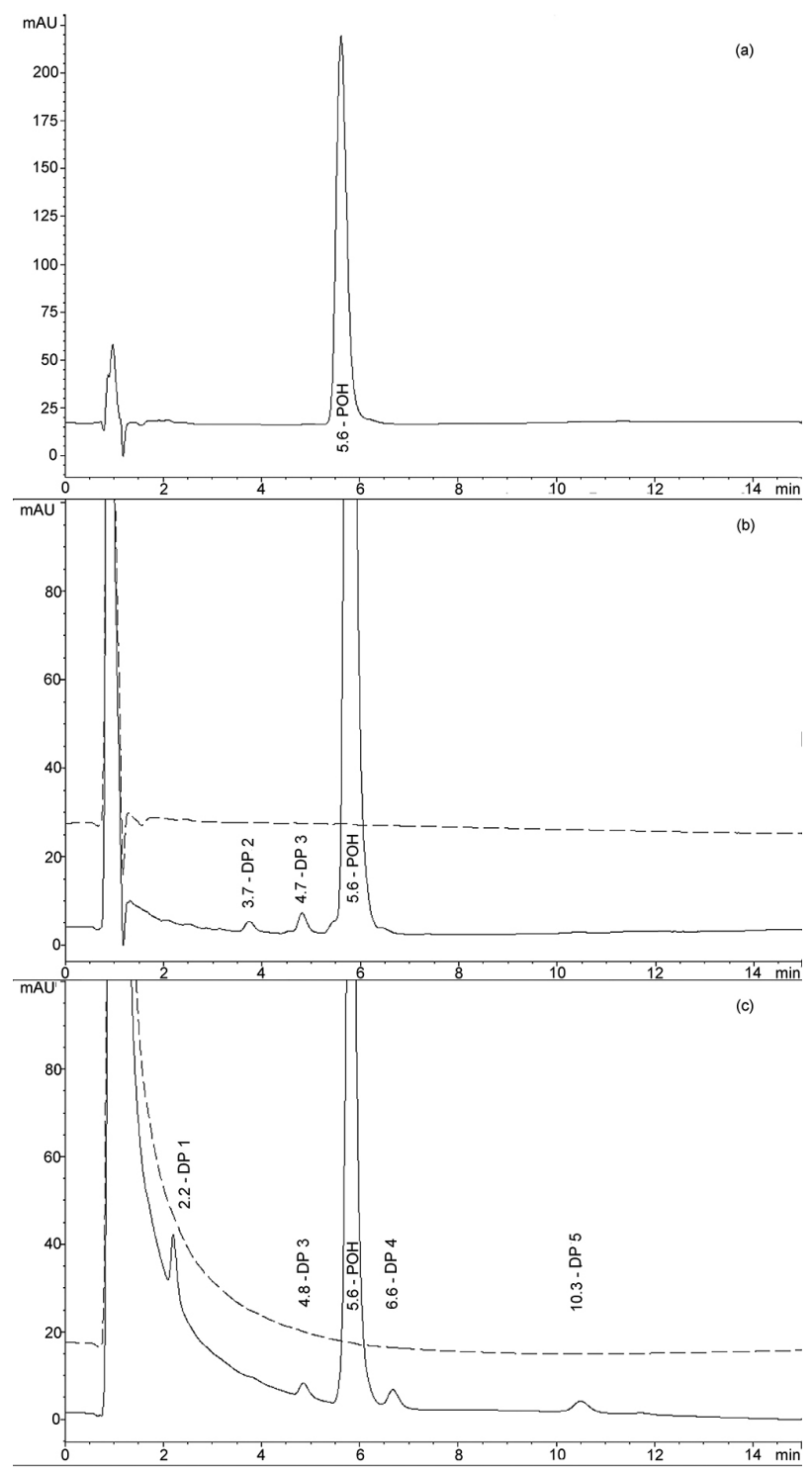

Figure 2. Chromatograms of: (a) control sample: sample freshly prepared from POH stock solution; (b) blank of alkaline conditions (dashed) and sample under alkaline conditions after $36 \mathrm{~h}$ of exposure (solid); (c) blank of acidic conditions (dashed), sample under acidic conditions after $36 \mathrm{~h}$ of exposure (solid).

below $10 \%$ without degradation peaks may suggest analytical variation, and values above $25 \%$ with degradation peaks may be related to the appearance of secondary degradation, which is not interesting. The exposure solutions were compared with the blanks for same exposure period, contributing to the preview of peak degradation.

After getting the primary degradations, the following step was to obtain an LC method to achieve good separation between $\mathrm{POH}$ and its degradation products. In this phase, several trials were conducted with different gradient mobile phases (containing acetonitrile or methanol and water). Methanol and acetonitrile showed good elution profiles with sharp and symmetrical peaks; however, acetonitrile:water produced a larger resolution than methanol: water. Furthermore, acetonitrile had a lower absorbance than methanol, especially for shorter wavelengths. The mobile phase containing a mixture of water:acetonitrile $(65: 35, \mathrm{v} / \mathrm{v})$ was found to be the most reliable at a flow rate of $350 \mu \mathrm{L} \mathrm{min}{ }^{-1}$. The elution was isocratic, providing greater reproducibility of the chromatographic parameters, such as capacity factor and resolution, between runs of same set of samples and among different sets of samples. Furthermore, in this case the use of elution gradient did not show advantageous since the total running time, including the time spent with the phase rebalance for the next run, was greater than that observed for isocratic elution. No further improvement in the analyte peaks was observed according to the oven column temperatures tested (25, 30 and $40{ }^{\circ} \mathrm{C}$ ), thus the column temperature was kept at $25^{\circ} \mathrm{C}$. The injection volume that provided the best result was $20 \mu \mathrm{L}$; lower values of injection volume decreased the signal to noise ratio and higher values contributed to broadening in the peaks. The chromatographic resolution was a choice factor for chromatographic conditions, resolution greater than 1.5 between adjacent peaks being considered as an acceptable value. The $\mathrm{POH}$ peak purity was also evaluated with a value greater than 0.990 being considered as acceptable. Under these chromatographic conditions, the obtained chromatograms were found to be quite sharp and well separated with a retention time of 5.6 min for $\mathrm{POH}$.

Through the forced degradation study it was possible to optimize the separation of $\mathrm{POH}$ from its degradation products. However, it is also essential that sample preparation could be able to differentiate the encapsulated drug from the non-encapsulated drug. Nanoparticles are colloidal systems and in the case of encapsulation efficiency measured indirectly, may occur a wrong estimation due to incomplete separation of free drug present in supernatant from the nanoparticles. In this work it was evaluated a procedure similar to already reported in literature. ${ }^{37,38}$ To ensure that free drug was completely separated by centrifugation, the supernatants obtained after each water wash step were analyzed separately. For this, each fraction was diluted with mobile phase to final volume of $10 \mathrm{~mL}$ and was subjected to ultrasonic bath for $5 \mathrm{~min}$, then diluted to appropriate concentration by dilution with mobile phase and filtered through a PVDF syringe filter $(13 \mathrm{~mm}$ diameter, $0.22 \mu \mathrm{m}$ pore size; Millipore Millex, Billerica, MA, USA) prior to injection. The first cleanup fraction showed very low amount of $\mathrm{POH}$, whilst in the second one, the presence of POH signal on HPLC was no longer observed. This evaluation was determined in triplicate and based on results it was considered sufficient for the 
complete separation of nanoparticles from free drug. So, to encapsulation efficiency test, the clear supernatant for assay was defined as a mixture of the three supernatants fractions, as described in sample preparation. In order to confirm the concentration of $\mathrm{POH}$ observed to the clear supernatant, the nanoparticles recovery by centrifugation were also analyzed. They were diluted in $2 \mathrm{~mL}$ of acetonitrile and subjected to ultrasonic bath for $5 \mathrm{~min}$. Then this solution was diluted to appropriate concentration by dilution with mobile phase and filtered through a PVDF syringe filter (13 mm diameter, $0.22 \mu \mathrm{m}$ pore size; Millipore Millex, Billerica, MA, USA) prior to injection. Acetonitrile was chosen because it is already used in the mobile phase and also because there have been reports in the literature confirming the solubility of polymer in this solvent. ${ }^{39,40}$ The sum of the results observed for the clear supernatant and recovered nanoparticles coincide with the theoretical value used in the formulation, indicating that in this case the indirect determination through the clear supernatant can be used to quantify the encapsulation efficiency. Since there is not consumption of nanoparticles by indirect determination, this procedure was chosen as a way to improve the yield of nanoparticles per batch.

Analytical validation parameters were assessed in order to evaluate the methodology developed here. The interference of the matrix components and degradation products was examined in the selectivity. By visual inspection no interferences were observed at the same retention time as the analyte of interest. The $\mathrm{POH}$ peak purity was assessed for all solutions forced to degradation showing values higher than 0.990 , as shown in Table 1 . The resolution between $\mathrm{POH}$ and adjacent degradation peaks was higher than 2 (Table 1).

Additionally, as shown in Table 2, the slope comparison of both curves (standard solution and spiked samples) showed no significant variation (RSD $<5 \%$; Student's $t$-test, $p>0.05$ ). When the slopes are equivalent the only matrix effect is the natural interference caused by the basic level of the analyte. Therefore, the selectivity of the developed method was found to be satisfactory.

Linearity was demonstrated by applying a linear regression model to fit the standard curves. The least squares regression model showed excellent correlation in the range of 20 to $80 \mu \mathrm{g} \mathrm{mL} \mathrm{m}^{-1}$, higher than 0.99 , in agreement with the ICH guidelines. ${ }^{35}$ The individual linear equations and coefficients of determination $\left(\mathrm{r}^{2}\right)$ were as follows: curve 1: $\mathrm{y}=35425.681 \mathrm{x}-42.440\left(\mathrm{r}^{2}=0.999\right)$; curve $2: \mathrm{y}=35093.889 \mathrm{x}-27.505\left(\mathrm{r}^{2}=0.999\right)$; curve 3: $\mathrm{y}=34798.712 \mathrm{x}-10.618\left(\mathrm{r}^{2}=0.999\right)$. Additionally, the equality of variances and homoscedasticity for each curve were assessed by Cochran's $C$ test, with homoscedasticity as the null hypothesis. ${ }^{41}$ The values of $C$ for the curves were: curve 1: 0.407 ; curve 2: 0.414; curve 3: 0.387 , all lower than the critical $C$ value of 0.561

Table 1. Retention times and peak purities for perillyl alcohol (POH) for different stress conditions evaluated and resolution between POH and near peaks

\begin{tabular}{lcccc}
\hline & POH retention time / min & POH peak purity & \multicolumn{2}{c}{ Resolution } \\
\cline { 4 - 5 } Acidic & 5.6 & 997.4 & 2.052 & DP4/POH \\
Alkaline & 5.6 & 999.8 & 2.629 & N/A \\
Oxidative & 5.6 & 999.9 & 2.749 & N/A \\
Thermal humidity & 5.6 & 999.9 & 2.657 & N/A \\
Dry heat & 5.6 & 999.9 & 2.379 & N/A \\
\hline
\end{tabular}

POH: perillyl alcohol; DP: degradation product observed; N/A: resolution was not applied because the degradation product was not observed for this stress condition.

Table 2. Statistical comparison of the slopes of the analytical curves for the determination of selectivity

\begin{tabular}{|c|c|c|c|c|c|c|}
\hline Curve & Slope & Average \pm SD & RSD & $t$-value ${ }^{\mathrm{a}}$ & $t_{\text {critical }}{ }^{\mathrm{b}}$ & $p$ value $^{\mathrm{c}}$ \\
\hline & 35425.68 & & \multirow{6}{*}{0.677} & \multirow{6}{*}{-1.02} & \multirow{6}{*}{1.706} & \multirow{6}{*}{0.365} \\
\hline \multirow[t]{3}{*}{ Standard solution } & 35093.89 & $35106.09 \pm 313.66$ & & & & \\
\hline & 34798.71 & & & & & \\
\hline & 35427.07 & & & & & \\
\hline \multirow[t]{2}{*}{ Spiked sample } & 35297.43 & $35303.05 \pm 121.32$ & & & & \\
\hline & 35184.63 & & & & & \\
\hline
\end{tabular}

${ }^{\mathrm{a}} t$-value based on $\mathrm{n}=21$ for standard solution and $\mathrm{n}=9$ for spiked sample; ${ }^{\mathrm{b}} t_{\text {critical }}$ considering $\mathrm{n}=26$ degrees of freedom at $5 \%$ significance level; ${ }^{\mathrm{c}}$ Student's $t$-test at $95 \%$ confidence level. SD: standard deviation; RSD: relative standard deviation. 
(seven curve points and three replicates for the variable y), suggesting that the null hypothesis is acceptable, i.e., the variances are homoscedastic. The significance of the slope coefficients of the estimated lines was verified by analysis of variance (ANOVA) and $F$-test (critical $F$-value $=4,381$, considering 1 numerator degree of freedom and $\mathrm{n}-2$ denominator degrees of freedom, with a $5 \%$ significance level). The values of $F$ for the curves were: curve 1: $\mathrm{F}_{(1,19)}=55577.6, p<0.05$; curve $2: \mathrm{F}_{(1,19)}=29997.5$, $p<0.05$; curve $3: \mathrm{F}_{(1,19)}=48517.1, p<0.05$. All values of $F$ were larger than the critical $F$-value, indicating that the proposed models are suitable for describing the phenomenon. Visual evaluation of residual plots showed that there was random behavior of distribution, showing no trend.

In order to define the accuracy of the chromatographic method for quantification of $\mathrm{POH}$, recovery studies were performed following the standard addition procedure. The average recovery percentages for low, medium and high levels of $\mathrm{POH}$ were $100.99 \pm 0.74 \%, 99.06 \pm 0.33 \%$ and $99.34 \pm 0.51 \%$, respectively. These results indicate a good agreement between the experimental and nominal concentrations of $\mathrm{POH}$. In this way, all measurements performed in this concentration range can be considered as in close agreement with the true $\mathrm{POH}$ concentration. The results obtained in the intra- and inter-days precision

Table 3. Repeatability and intermediate precision for perillyl alcohol

\begin{tabular}{|c|c|c|c|c|c|c|c|c|}
\hline \multirow{3}{*}{ Sample } & \multicolumn{8}{|c|}{ Precision } \\
\hline & \multicolumn{3}{|c|}{ Repeatability } & \multicolumn{3}{|c|}{ Intermediate precision } & \multirow[b]{2}{*}{$t$-value ${ }^{\mathrm{a}}$} & \multirow[b]{2}{*}{$t_{\text {critical }}$} \\
\hline & $\begin{array}{c}\text { Assay } \pm \mathrm{SD} \\
(\mathrm{n}=3) /\left(\mu \mathrm{g} \mathrm{mL}^{-1}\right)\end{array}$ & $\begin{array}{l}\text { Average } \pm \text { SD } \\
\quad(\mathrm{n}=9)\end{array}$ & $\begin{array}{c}\text { RSD } \\
(\mathrm{n}=9) / \%\end{array}$ & $\begin{array}{c}\text { Assay } \pm \mathrm{SD} \\
(\mathrm{n}=3) /\left(\mu \mathrm{g} \mathrm{mL} L^{-1}\right)\end{array}$ & $\begin{array}{l}\text { Average } \pm \text { SD } \\
\quad(\mathrm{n}=9)\end{array}$ & $\begin{array}{c}\text { RSD } \\
(\mathrm{n}=9) / \%\end{array}$ & & \\
\hline & $19.2 \pm 0.028$ & & & $18.4 \pm 0.149$ & & & & \\
\hline \multirow[t]{3}{*}{ Low } & $19.7 \pm 0.023$ & $19.8 \pm 0.54$ & 2.75 & $19.6 \pm 0.014$ & $18.9 \pm 0.55$ & 2.91 & -1.946 & 2.119 \\
\hline & $20.4 \pm 0.063$ & & & $18.7 \pm 0.028$ & & & & \\
\hline & $49.9 \pm 0.128$ & & & $51.0 \pm 0.056$ & & & & \\
\hline \multirow[t]{3}{*}{ Medium } & $49.6 \pm 0.428$ & $49.8 \pm 0.28$ & 0.56 & $49.5 \pm 0.497$ & $50.0 \pm 0.78$ & 1.55 & 0.992 & 2.228 \\
\hline & $49.8 \pm 0.073$ & & & $49.6 \pm 0.119$ & & & & \\
\hline & $80.8 \pm 0.045$ & & & $80.6 \pm 0.020$ & & & & \\
\hline \multirow[t]{2}{*}{ High } & $80.5 \pm 0.467$ & $80.7 \pm 0.41$ & 0.51 & $80.1 \pm 0.060$ & $80.5 \pm 0.30$ & 0.37 & 1.909 & 2.119 \\
\hline & $80.8 \pm 0.618$ & & & $80.8 \pm 0.688$ & & & & \\
\hline
\end{tabular}

a Student's $t$-test at 95\% confidence level (low $p$ value: 0.069 ; medium $p$ value: 0.334 ; high $p$ value: 0.074 ).

Table 4. Effect of the variation of analytical parameters on the recovery of perillyl alcohol in sample and standard solutions

\begin{tabular}{|c|c|c|c|}
\hline Parameter & Analytical solution & Assay $\pm \mathrm{SD}(\mathrm{n}=3) /\left(\mu \mathrm{g} \mathrm{mL} L^{-1}\right)$ & Recovery $\pm \operatorname{SD}(n=3) / \%$ \\
\hline \multirow[t]{2}{*}{ Control } & standard & $52.1 \pm 0.622$ & - \\
\hline & sample & $48.2 \pm 0.080$ & - \\
\hline \multirow[t]{2}{*}{ Flow $0.34 \mathrm{~mL} \mathrm{~min}^{-1}$} & standard & $52.0 \pm 0.042$ & $99.81 \pm 0.08$ \\
\hline & sample & $48.2 \pm 0.078$ & $100.08 \pm 0.16$ \\
\hline \multirow[t]{2}{*}{ Flow $0.36 \mathrm{~mL} \mathrm{~min}^{-1}$} & standard & $52.1 \pm 0.562$ & $100.02 \pm 1.09$ \\
\hline & sample & $49.0 \pm 0.064$ & $101.66 \pm 0.13$ \\
\hline \multirow[t]{2}{*}{ Column oven $23^{\circ} \mathrm{C}$} & standard & $51.8 \pm 0.149$ & $99.42 \pm 0.29$ \\
\hline & sample & $48.3 \pm 0.337$ & $100.21 \pm 0.70$ \\
\hline \multirow[t]{2}{*}{ Column oven $28^{\circ} \mathrm{C}$} & standard & $52.1 \pm 0.109$ & $100.06 \pm 0.21$ \\
\hline & sample & $48.3 \pm 0.057$ & $100.21 \pm 0.12$ \\
\hline \multirow[t]{2}{*}{$34 \%$ acetonitrile } & standard & $52.1 \pm 0.031$ & $100.09 \pm 0.06$ \\
\hline & sample & $47.9 \pm 0.138$ & $99.38 \pm 0.29$ \\
\hline \multirow[t]{2}{*}{$36 \%$ acetonitrile } & standard & $53.0 \pm 0.451$ & $101.73 \pm 0.87$ \\
\hline & sample & $48.2 \pm 0.065$ & $100.10 \pm 0.14$ \\
\hline \multirow[t]{2}{*}{ Column lot } & standard & $52.1 \pm 0.179$ & $100.06 \pm 0.35$ \\
\hline & sample & $49.1 \pm 0.182$ & $101.87 \pm 0.38$ \\
\hline
\end{tabular}


determination experiments have been expressed as RSD (Table 3). Small RSD values were found for both intra-day and inter-days analyses. The intermediate precision was evaluated by Student's $t$-test for each level between the different analysts. The values obtained for $t$-value were lower than $t_{\text {critical }}$, highlighting that the means are statistically equivalent (Student's $t$-test, $p>0.05$ ).

Table 4 summarizes the results found in the robustness test. None of the alterations made to the method affected the determination of $\mathrm{POH}$ and no significant differences among these experimental effects were observed when compared to the assay of the standard and control samples. The peak purity values for $\mathrm{POH}$ were larger than 0.99 in all evaluated conditions, indicating no coelution. The resolution between $\mathrm{POH}$ and degradation peaks was evaluated and all situations showed good chromatographic separation, with resolutions larger than 1.5. Even so, the method was considered robust.

The stability tests were designed to take into consideration the anticipated conditions of handling real samples. The recovery results for $\mathrm{POH}$ stock standard solutions were, respectively, 99.60, 99.48 and $100.50 \%$ for long-term stability $\left(2-8{ }^{\circ} \mathrm{C}\right.$ for 7,14 and 30 days). The recovery result for sample preparation under benchtop stability (sample manager at $20{ }^{\circ} \mathrm{C}$ for $12 \mathrm{~h}$ ) was $99.61 \%$. Under the tested conditions, the results were not statistically different from the results of freshly prepared standard solutions ( $p>0.05$, Student's $t$-test, 95\% confidence level).

Since the encapsulation efficiency represents the amount of drug incorporated in nanostructured system, optimize the loading capacity during development phase can improve therapeutic goal. In furtherance of this objective, the proper evaluation of encapsulation efficiency plays a crucial role, being the development of analytical method and subsequent analytical validation important steps prior to the pharmacotechnical development. Nanoparticles containing $\mathrm{POH}$ were obtained by the single-emulsion solvent-evaporation technique and presented particle size of $173.15 \pm 4.05 \mathrm{~nm}$. The zeta potential was negative: $-19.57 \pm 1.36 \mathrm{mV}$. The encapsulation efficiency of $\mathrm{POH}$ in nanoparticles was determined in triplicate by the method developed and validated previously in this work. The free $\mathrm{POH}$ concentration in sample preparation was determined to be $47.82 \pm 0.04 \mu \mathrm{g} \mathrm{mL}^{-1}$, within the analytical range determined in the analytical validation. The encapsulation efficiency was $74.45 \pm 0.02 \%$, calculated by the difference of the amount of $\mathrm{POH}$ initially added to the formulation (9.75 mg (> 96.0\%), total dilution volume of $50 \mathrm{~mL}$ ). Degradation products were not observed in the analyzed nanoparticles, indicating that the production steps that could be more aggressive to the drug, such as the use of ultrasonication and vacuum system temperature, do not favor chemical degradation.

\section{Conclusions}

A suitable stability-indicating method was developed for both determination of $\mathrm{POH}$ encapsulation efficiency in polymeric nanoparticles formulation and evaluating the presence of related degradation products. The developed method was found to be selective and efficient as validated according to ICH guidelines. The results of the validation study suggest that the method is selective, linear, precise, accurate and robust. The method was successfully applied to determine the encapsulation efficiency of $\mathrm{POH}$ in polymeric nanoparticles. The presence of degradation products was not observed in nanoparticles freshly produced, indicating that the production steps that could be more aggressive to the drug do not favor its chemical degradation. In addition, the chromatographic method could be further employed in performance studies of $\mathrm{POH}$ formulations, such as stability and in vitro drug release.

\section{Acknowledgments}

The authors thank the Brazilian agencies CAPES and CNPq for fellowships.

\section{References}

1. Crowell, P. L.; Elson, C. E. In Handbook of Nutraceuticals and Functional Foods; Wildman, R. E. C., ed.; CRC Press LLC: Boca Raton, FL, 2001, p. 31.

2. Chen, T. C.; Fonseca, C. O. D.; Schönthal, A. H.; Am. J. Cancer Res. 2015, 5(5), 1580.

3. Yeruva, L.; Pierre, J. K.; Elegbede, A.; Wang, C. R.; Carper, S. W.; Cancer Lett. 2007, 257, 216.

4. Elegbede, J. A.; Flores, R.; Wang, R. C.; Life Sci. 2003, 73, 2831.

5. Wiseman, D. A.; Werner, S. R.; Crowell, P. L.; J. Pharmacol. Exp. Ther. 2007, 320, 1163.

6. Clark, S. S.; Perman, S. M.; Sahin, M. B.; Jenkins, G.; Elegbede, J. A.; Leukemia 2002, 16, 213.

7. Fonseca, C. O.; Gattass, C. R.; Linden, R.; Carvalho, M. G.; Futuro, D.; Santos, T. T.; J. Bras. Neurocir. 2007, 18, 7.

8. Azzoli, C. G.; Miller, V. A.; Ng, K. K.; Krug, L. M.; Spriggs, D. R.; Tong, W. P.; Cancer Chemother. Pharmacol. 2003, 51, 493.

9. Bailey, H. H.; Wilding, G.; Tutsch, K. D.; Arzzomanian, R. Z.; Albert, D.; Feierabend, C.; Cancer Chemother. Pharmacol. 2004, 54, 368. 
10. Morgan-Meadows, S.; Dubey, S.; Gould, M.; Tutsch, K.; Marnocha, R.; Arzzomanin, R.; Cancer Chemother. Pharmacol. 2003, 52, 361 .

11. Danhier, F.; Ansorena, E.; Silva, J. M.; Coco, R.; Breton, A. L.; Préat, V.; J. Controlled Release 2012, 161(2), 505.

12. Khalil, N. M.; Nascimento, T. C. F.; Casa, D. M.; Dalmolin, L. F.; Mattos, A. C.; Hoss, I.; Romano, M. A.; Mainardes, R. M.; Colloids Surf., B 2013, 101, 353.

13. Khalil, N. M.; Carraro, E.; Cótica, L. F; Mainardes, R. M.; Expert Opin. Drug Delivery 2011, 8, 95.

14. Kumari, A.; Yadav, S. K.; Yadav, S. C.; Colloids Surf., B 2010 , $75,1$.

15. Khalil, N. M.; Mainardes, R. M.; Curr. Drug Delivery 2009, 6, 261.

16. Frank, A.; Pridgen, E.; Molnar, L. K.; Farokhzad, O. C.; Mol. Pharmacol. 2008, 5, 505.

17. Leroux, J. C.; Allemann, E.; De Jaeghere, F.; Doelker, E.; Gurny, R. L.; J. Controlled Release 1996, 39, 339.

18. Schaffazick, S. R.; Guterres, S. S.; Quim. Nova 2003, 26(5), 726.

19. Zhang, Z.; Chen, H.; Chan, K. K.; Budd, T.; Ganapathi, R.; J. Chromatogr. B: Biomed. Sci. Appl. 1999, 728(1), 85.

20. Schimidt, L.; Belov, V. N.; Göen, T.; Anal. Chim. Acta 2013, 793(2), 26.

21. Matysik, S.; Matysik, F. M.; Microchim. Acta 2009, 166, 109.

22. Sandner, F.; Fornara, J.; Dott, W.; Hollender, J.; J. Chromatogr. B: Anal. Technol. Biomed. Life Sci. 2002, 780(2), 225.

23. Song, H. S.; Sawamura, M.; Ito, T.; Kawashimo, K.; Ukeda, H.; Flavour Fragrance J. 2000, 15, 245.

24. Vichi, S.; Riu-Aumatell, M.; Mora-Pons, M.; Guadayol, J. M.; Buxaderas, S.; López-Tamames, E.; Food Chem. 2007, 105(4), 1748.

25. Gupta, A.; Stratton, S. P.; Myrdal, P. B.; J. Pharm. Biomed. Anal. 2005, 37(3), 447.

26. Ikechukwu, E. E.; Phillips, L. R.; Wolfe, T. L.; Esmail, T. S.; J. Chromatogr. B: Biomed. Sci. Appl. 1997, 688(2), 354.

27. Hua, H. Y.; Zhao, Y. X.; Liu, L.; Ye, Q. X.; Ge, S. W.; J. Pharm. Biomed. Anal. 2008, 48(4), 1201.

28. Tao, L.; Pereira, M. A.; J. Chromatogr. A 1998, 793(1), 71.

29. Hjertman, M.; Wejde, J.; Larsson, O.; Biochem. Biophys. Res. Commun. 2001, 288(3), 736.
30. Boon, P. J.; Van Der Boon, D.; Mulder, G. J.; Toxicol. Appl. Pharmacol. 2000, 167(1), 55.

31. Meesters, R. J.; Duisken, M.; Jähnigen, H.; Hollender, J.; J. Chromatogr. B: Anal. Technol. Biomed. Life Sci. 2008, 875(2), 444.

32. ICH, International Conference on Harmonization of Technical Requirements for Registration of Pharmaceuticals for Human Use, Q3A(R2); Impurities in New Drug Substances; ICH: Geneva, 2006.

33. ICH, International Conference on Harmonization of Technical Requirements for Registration of Pharmaceuticals for Human Use, Q3B(R2); Impurities in New Drug Products; ICH: Geneva, 2006.

34. Li, M.; Rouaud, O.; Poncelet, D.; Int. J. Pharm. 2008, 363, 26.

35. ICH, International Conference on Harmonization of Technical Requirements for Registration of Pharmaceuticals for Human Use, Q2B(R1); Validation of Analytical Procedures: Text and Methodology; ICH: Geneva, 2005.

36. ICH, International Conference on Harmonization of Technical Requirements for Registration of Pharmaceuticals for Human Use, Q1B; Photostability Testing of New Active Substances and Medicinal Products: Text and Methodology; ICH: Geneva, 1998.

37. Alves, A. C. S.; Mainardes, R. M.; Khalil, N. M.; Mater. Sci. Eng., C 2016, 60, 126.

38. Mainardes, R. M.; Gremião, M. P.; Brunetti, I. L.; da Fonseca, L. M.; Khalil, N. M.; J. Pharm. Sci. 2009, 98(1), 257.

39. Xie, H.; Smith, J. W.; J. Nanobiotechnol. 2010, 8, 18.

40. Morales-Cruz, M.; Flores-Fernandez, G. M.; Morales-Cruz, M.; Orellano, E. A.; Rodriguez-Martinez, J. A.; Ruiz, M.; Griebenow, K.; Results Pharma Sci. 2012, 2, 79.

41. ISO, International Organization for Standardization; ISO 5725 3:1994 Accuracy (Trueness and Precision) of Measurement Methods and Results. Part 3: Intermediate Measures of Precision of a Standard Measurement Method; ISO: Geneva, 1994.

Submitted: November 1, 2016

Published online: June 6, 2017 